REFERENCES:

[1] Scher, et al. Nat Rev Rheum 2019 In Press.

Table. Multivariable HRs for the risk for PsA among patients with psoriasis.

\begin{tabular}{lccc}
\hline & All $^{*}$ & Women & Men \\
\hline Age & $0.99(0.99-1.00)$ & $1.00(0.99-1.00)$ & $0.99(0.99-0.99)$ \\
Male Sex & $1.09(1.02-1.16)$ & & \\
Obesity & $1.31(1.16-1.48)$ & $1.30(1.11-1.53)$ & $1.35(1.12-1.64)$ \\
Depression & $1.19(1.06-1.33)$ & $1.19(1.04-1.37)$ & $1.23(1.01-1.49)$ \\
Fatigue & $1.61(1.43-1.81)$ & $1.50(1.30-1.75)$ & $1.91(1.59-2.29)$ \\
Anemia & $1.48(1.29-1.70)$ & $1.62(1.37-1.92)$ & \\
Uveitis & $2.48(1.41-4.38)$ & $2.90(1.38-6.08)$ & \\
Sepsis & $1.64(1.07-2.52)$ & $2.39(1.41-4.03)$ & \\
Liver Disease & $1.31(1.06-1.62)$ & & $1.40(1.04-1.88)$ \\
Hiddradenitis Suppertiva & $2.16(1.16-4.02)$ & & $4.04(1.68-9.74)$ \\
Hypertension & $1.16(1.07-1.26)$ & & $1.18(1.05-1.33)$ \\
Osteomyelitis & $2.17(1.29-3.67)$ & & \\
Celiac Disease & $1.98(1.10-3.58)$ & & \\
HIV & $0.24(0.06-0.96)$ & & \\
Any infection & $1.13(1.04-1.22)$ & & \\
Restless Leg Syndrome & & $1.55(1.06-2.28)$ & \\
Salmonella & & $1.38-5.29)$ \\
Cellulitis & & $1.23(1.06-1.43)$ & \\
Diabetes & & & $1.62(1.00-2.62)$ \\
Irritable Bowel Syndrome & & & $4.40(1.10-17.62)$ \\
Venous Thromboembolism & & &
\end{tabular}

Disclosure of Interests: Alexis Ogdie Grant/research support from: (To my university) Novartis, Pfizer, Grant/research support from: Novartis, Pfizer, Grant/ research support from: Novartis, Pfizer, Grant/research support from: Novartis, Pfizer, Consultant for: AbbVie, Bristol-Myers Squibb, Celgene, Corrona, Eli Lilly and Company, Novartis, Pfizer, and Takeda, Consultant for: AbbVie, Amgen, Bristol-Myers Squibb, Celgene, Corrona, Eli Lilly, Novartis, Pfizer Inc, Takeda, Consultant for: Abbvie, Amgen, BMS, Celgene, Corrona, Lilly, Novartis, Pfizer, Takeda, Consultant for: Abbvie, Amgen, BMS, Celgene, Corrona, Lilly, Novartis, Pfizer, Takeda, Jose Scher Grant/research support from: Pfizer, Novartis, Consultant for: Janssen, UCB, Novartis, Amgen, Shiyu Vanessa Wang: None declared, Daniel Shin: None declared, David Margolis Grant/research support from: Research funds from Valeant to the trustees of the university of pennsylvania, Consultant for: Data monitoring boards for Johnson and Johnson, Junko Takeshita Grant/research support from: Pfizer (to the Trustees of the University of Pennsylvania), Paid instructor for: Continuing medical education work related to psoriasis that was supported indirectly by Eli Lilly., Hyon Choi: None declared, Thorvardur Jon Love Consultant for: Received reimbursment from Celgene for speaking about guidelines for the treatment of psoriatic arthritis, Christopher $\mathrm{T}$. Ritchlin Grant/research support from: AbbVie, Amgen, UCB Pharma, Consultant for: AbbVie, Amgen, Lilly, Novartis, Pfizer, UCB Pharma, Joel Gelfand Grant/ research support from: Research grants (to the Trustees of the University of Pennsylvania) from Abbvie, Boehringer Ingelheim, Janssen, Novartis Corp, Celgene, Ortho Dermatologics, and Pfizer Inc., Consultant for: BMS, Boehringer Ingelheim, Janssen Biologics, Novartis Corp, UCB (DSMB), Sanofi, and Pfizer Inc., Paid instructor for: Received payment for continuing medical education work related to psoriasis that was supported indirectly by Lilly, Ortho Dermatologics and Novartis., Joseph F. Merola Consultant for: Biogen IDEC, Abbvie, Amgen, Eli Lilly and Company, Novartis, Pfizer, Janssen, UCB, Samumed, Celgene, Sanofi Regeneron, Merck, and GSK

DOI: 10.1136/annrheumdis-2019-eular.4390

THURSDAY, 13 JUNE 2019

"Rheumatoid arthritis - looking before, looking forward!"

\section{OP0116 JOINT EROSIONS VISIBLE ON ULTRASOUND PREDICT ARTHRITIS DEVELOPMENT IN PATIENTS WITH ACPA AND MUSCULOSKELETAL PAIN BUT NO SWOLLEN JOINTS}

Michael Ziegelasch ${ }^{1}$, Emma Eloff ${ }^{1}$, Hilde Berner Hammer ${ }^{2}$, Jan Cedergren ${ }^{1}$, Klara Martinsson ${ }^{1}$, Åsa Reckner ${ }^{1}$, Thomas Skogh ${ }^{1}$, Mattias Magnusson ${ }^{1}$, Alf Kastbom ${ }^{1}$. 'Linköping University, Dpt of Rheumatology and Dpt of Clinical and Experimental Medicine, Linköping, Sweden; ${ }^{2}$ Diakonhjemmet Hospital, Department of Rheumatology, Oslo, Norway

Background: Anti-citrullinated protein antibodies (ACPA) are associated with an increased risk of developing rheumatoid arthritis (RA), and in particular erosive disease. Detection of joint inflammation prior to clinical synovitis may improve treatment decisions in early disease.

Objectives: We sought to determine the value of ultrasound (US) to predict arthritis development among ACPA positive patients with musculoskeletal (MSK) pain. Methods: We prospectively followed 82 ACPA-positive patients with MSK pain but without arthritis upon baseline clinical examination (mean follow-up 68 months, range 23-91). US at baseline assessed joint erosions, synovial hypertrophy in grey scale (GS), and inflammatory activity judged by power Doppler (PD) in 36 small joints in hands and feet. We used a ProFocus system (BK Medical) with pulse repetition frequency $0.8 \mathrm{kHz}$ for $\mathrm{PD}$ grading. The US and $\mathrm{PD}$ results were blinded to patients and treating rheumatologists during the initial 3 years. US findings among patients were compared to 100 age-matched healthy blood donors Arthritis development during follow-up of patients was determined by clinical examination by an experienced rheumatologist. Associations between baseline US findings and arthritis development were tested by Cox regression analysis with adjustment for sex, age, symptom duration, smoking habits, erythrocyte sedimentation rate, C-reactive protein level, rheumatoid factor, and ACPA levels.

Results: Significantly more patient joints had synovial hypertrophy (GS score $>0$ ) compared to control joints in metacarpophalangeal (MCP) $(5.2 \%$ vs. $2.5 \%$; $\mathrm{p}<0.001)$ and proximal interphalangeal (PIP) joints $2-5$ (6.6 vs. $1.5 \% ; \mathrm{p}<0.001)$. In contrast, metatarsophalangeal (MTP) joints $1-5$ of the controls were more often scored GS $>0$ compared to patient joints ( $49 \%$ vs. $24 \%$; $p<0.001)$. Positive PD $(>0)$ occurred significantly more often in patient joints compared to the controls in all joint areas $(p<0.05)$. At patient level, the mean sum score of all investigated joints was higher among patients than controls, regarding GS as well as PD $(\mathrm{p}<0.001$ for both). 13 patients $(16 \%)$, but none of the controls, had erosions detected on US $(p<0.001)$. During follow-up of patients, $39(48 \%)$ developed arthritis after median 25 weeks (range 5-302). Arthritis development was significantly more common among patients with baseline US erosions (10 out of 13 $77 \%$ ) compared to those without ( 29 out of $69 ; 42 \%, p=0.032$ ). This remained sig nificant also in Cox regression adjusting for potential confounders (Hazard ratio $=4.2,95 \% \mathrm{Cl} 1.7-10.4, \mathrm{p}=0.002)$. Out of the 13 erosions detected on US, 4 could be identified on conventional radiographs. Neither GS nor PD findings were significantly associated with arthritis development.

Conclusion: Arthritis-related US findings are more common among patients at increased risk of RA compared to healthy controls, but with site-specific differences. Erosions detected on US predicted arthritis development. Thus, US assess ment of erosions improves risk-stratification of ACPA-positive patients without swollen joints, and potentially identifies patients eligible for very early pharmacotherapy.

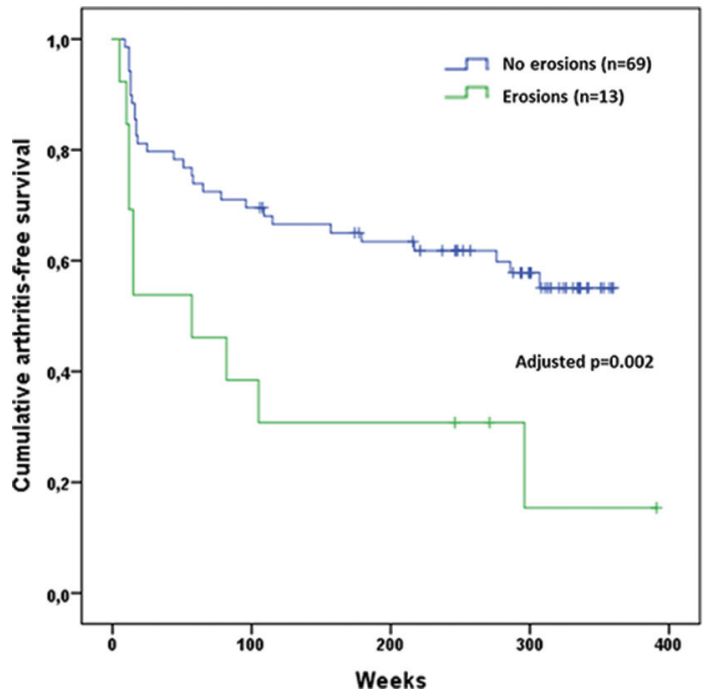

Figure 1. Survival plot illustrating progression to arthritis during follow-up in relation to the presence of ultrasound erosions at baseline among patients with anti-citrullinated protein antibodies and musculoskeletal pain.

Disclosure of Interests: Michael Ziegelasch Consultant for: AbbVie, MSD, Pfizer, and BK-Medical, Emma Eloff: None declared, Hilde Berner Hammer Speakers bureau: speakers fee from AbbVie, Bristol-Myers

Squibb, Roche, UCB Pharma and Pfizer, Jan Cedergren: None declared, Klara Martinsson: None declared, Åsa Reckner: None declared, Thomas Skogh: None declared, Mattias Magnusson: None declared, Alf Kastbom Consultant for: Roche and Pfizer, Employee of: Sanofi, Speakers bureau: UCB and BMS DOI: 10.1136/annrheumdis-2019-eular.1594 